\title{
Casual sexual experience abroad in patients attending an STD clinic and at high risk for HIV infection
}

\author{
K-S Tveit, A Nilsen, A Nyfors
}

\begin{abstract}
Objective-To study possible "import" routes of HIV infection to Norway (by obtaining information on casual sexual contacts abroad from patients attending an STD clinic), and to assess their behavioural risk factors (such as alcohol intake, use of condom) for HIV infection. Design and Setting-Patients visiting the clinic for sexually transmitted diseases (STD), April-June 1989, received a questionnaire.
\end{abstract}

Subjects-606 consecutive persons of whom 599 agreed $(98 \cdot 8 \%)$ to participate. We grouped the patients in four categories. 1: Sex with a prostitute during the last 5 years, 2: Homosexuals/bisexuals, 3: prostitutes/intravenous drug abusers (IVDUs) and 4: Other heterosexuals. Results-245 patients (41\%) reported having a casual sex partner abroad (M: 182, F: 63), mainly in Europe, particularly in Spain, Denmark and Greece. Outside Europe such contacts were most frequently reported from USA, Brazil and Thailand. Among men who had had sex with a prostitute, $93.5 \%$ reported such sex abroad (homosexuals/bisexuals: $63.6 \%$, prostitutes/IVDUs: $66 \cdot 7 \%$, "other heterosexuals: $32 \cdot 1 \%)$. Homosexual bisexual men with casual partner(s) abroad used a condom more frequently than did others.

Conclusion-245 of 599 persons reported casual sex abroad during 1985-1989, and the different "risk groups" reported countries where most HIV infected persons belonged to their own "risk group". We have reason to believe that alcohol intake increased the likelihood of casual sexual activity and decreased the use of condom. Norwegian travellers need more information on the risks of casual sex abroad, the use of condoms and the combination of alcohol intake and casual sex.

(Genitourin Med 1994;70:12-14)

Haukeland University Hospital, Bergen, Norway.

K-S Tveit

A Nilsen

A Nyfors

Address correspondence to:

Dr K-S Tveit, Section of

Venereology, Department of

Dermatology, Haukeland

University Hospital, Bergen,

N-5021 Norway.

Accepted for publication

1 October 1993 out to describe in detail casual sex activity abroad among "high risk" groups attending an STD clinic. Therefore we undertook a study to demonstrate possible "import" routes of HIV infection to Norway and to study the sexual behaviour of patients attending an STD clinic, an important group at risk for HIV infection. ${ }^{27}$

\section{Patients and methods}

We approached all new patients (606) visiting the STD clinic at the University Hospital in Bergen, Norway, April-June 1989, of whom $599(98 \cdot 8 \%)$ agreed to participate. The inclusion criteria were that the patient wanted to be examined for any STD, and that it was the first attendance for that particular reason. We did not register the nationality, skin colour, race or religion of the respondents. A questionnaire, written in Norwegian, was given to the patient after the medical history and the clinical examination had been completed. One of the authors went through the questionnaire together with the patient before the patient left the clinic, to minimise the number of unanswered questions. We do not know the number of patients with STDs dependent upon laboratory diagnosis because the study was anonymous and voluntary and we did not do any follow up.

The respondents reported casual sexual contact(s) abroad, both paid and unpaid sex, from 1985 to 1989 , named the country/ countries where this activity had taken place, noted whether they used a condom or not and if they were drunk when having a casual sex partner. We only registered the sexual behaviour abroad of the patients during the previous 5 years. Respondents' sexual relationship with prostitutes was dealt with separately from their relationship with unpaid casual partners.

The patients were grouped in four categories. 1: Men who had sex with a prostitute during the last 5 years in Norway or abroad, 2: Homosexuals/bisexuals, 3: Prostitutes/ intravenous drug users (IVDUs) and 4: Other heterosexuals. Since $50 \%$ of the prostitutes were IVDUs, they were grouped

We examined the frequency of and the country for the sex contacts, in homosexuals, bisexuals, IVDUs as well as men paying for sexual services. We then compared the findings (such as alcohol intake, use of condom) in the different groups to estimate their risk of together. HIV infection.

Introduction
The variation observed in the prevalence of
the HIV infection in the different countries
depends on various factors including the dif-
ferent times of introduction and the spread of
HIV in a defined area. ${ }^{12}$ The latter is-among
others-linked with the travelling activity of
people..$^{3-6}$
Very few studies, if any, have been carried

Introduction
The variation observed in the prevalence of
the HIV infection in the different countries
depends on various factors including the dif-
ferent times of introduction and the spread of
HIV in a defined area. ${ }^{12}$ The latter is-among
others-linked with the travelling activity of
people..$^{3-6}$
Very few studies, if any, have been carried

Introduction
The variation observed in the prevalence of
the HIV infection in the different countries
depends on various factors including the dif-
ferent times of introduction and the spread of
HIV in a defined area. ${ }^{12}$ The latter is-among
others-linked with the travelling activity of
people..$^{3-6}$
Very few studies, if any, have been carried

Introduction
The variation observed in the prevalence of
the HIV infection in the different countries
depends on various factors including the dif-
ferent times of introduction and the spread of
HIV in a defined area. ${ }^{12}$ The latter is-among
others-linked with the travelling activity of
people..$^{3-6}$
Very few studies, if any, have been carried

Introduction
The variation observed in the prevalence of
the HIV infection in the different countries
depends on various factors including the dif-
ferent times of introduction and the spread of
HIV in a defined area. ${ }^{2}$ The latter is - among
others-linked with the travelling activity of
people..$^{3-6}$
Very few studies, if any, have been carried 
For statistical analyses, the chi square method was used ${ }^{8}$; a $p$ value of $<0.05$ was considered significant. Statistical analyses were performed using the Statview package designed for Macintosh. ${ }^{9}$

\section{Results}

The number of persons in the different groups is shown in table 1 and 2 .

Altogether $245 / 599(40.9 \%)$ of the patients reported a casual sex-partner abroad from 1985-1989 (men: 182/411; 44.3\% and women: $63 / 188 ; 33.5 \%, p=0.013)$. Men who reported sex with a prostitute also had a casual sex partner abroad more frequently $(58 / 62 ; 93.5 \%)$ than did IVDUs/prostitutes $(14 / 21 ; 66 \cdot 7 \%$, chi square: $9 \cdot 86, p=0.002)$, homosexuals/bisexuals (14/22; 63.6\%, chi square: $11.865, p<0.001)$ and "other heterosexuals" (162/497; $32.6 \%$, chi square: $85.807, p<0.001)$. Only men had sex with prostitutes abroad, while $8 / 14(57 \cdot 1 \%)$ of the prostitutes/IVDUs, $52 / 162(32 \cdot 1 \%)$ of the "other heterosexuals" and $4 / 14(28.6 \%)$ of the homosexuals/bisexuals were women.

Men were more likely to report contacts in north-east European countries (107/411; $26 \%$;) compared with women (22/188; $11.7 \%$, chi square: $15.68, p<0.001)$. On the other hand, more women $(49 / 188 ; 26.1 \%)$ than men $(83 / 411 ; 20.2 \%)$ reported casual sexual practice in a south European country $(p>0.05)$. Very few women (5) had any sexual experience in a country outside Europe.

In table 1 , we see that men paying for sexual services had their casual sexual experience in more countries than did the other groups.

\section{Countries reported}

In table 2 is shown the distribution of casual sexual contacts in different parts of the world. The difference between men paying for sex and "other heterosexuals" was statistically significant (chi square: 57.454, $p<0.001$ ).

Table 1 Number of countries where casual sex took place

\begin{tabular}{lccc}
\hline $\begin{array}{l}\text { Number of } \\
\text { countries }\end{array}$ & $\begin{array}{l}\text { Sex with } \\
\text { prostitutes }\end{array}$ & $\begin{array}{l}\text { Homosexuals/ } \\
\text { bisexuals }\end{array}$ & IVDUs/prostitutes \\
\hline 1 & $19(32 \cdot 8 \%)$ & $7(50 \%)$ & $5(35 \cdot 7 \%)$ \\
2 & $11(19 \cdot 0 \%)$ & $3(21 \cdot 4 \%)$ & $4(28 \cdot 6 \%)$ \\
3 & $11(19 \cdot 0 \%)$ & $1(7 \cdot 1 \%)$ & $3(21 \cdot 4 \%)$ \\
4 or more & $17(29 \cdot 3 \%)$ & $3(21 \cdot 4 \%)$ & $2(14 \cdot 3 \%)$ \\
Total & $100 \%$ & $100 \%$ & $100 \%$ \\
\hline
\end{tabular}

Paying for sexual services was more likely in the north European countries (38/62; 61.3\%, chi square: $33.52, p<0.001$ ) while they had mainly unpaid sex in the Mediterranean area $(17 / 62 ; 27 \cdot 4 \%)$. The IVDUs/prostitutes admitted casual sex most frequently in south Europe $(11 / 21 ; 52 \cdot 4 \%)$.

Outside the western world most (29/40; $72.5 \%$ ) of the sex partners were prostitutes (chi square: $164.414, p<0.001$ ). None of the homosexuals/bisexuals or prostitutes/ IVDUs reported any sexual activity in these countries.

There was no significant difference in the travelling pattern between the homosexuals/ bisexuals and the IVDUs/prostitutes.

Alcohol intake and use of condom

Among men paying for sexual services 32/49 $(65.3 \%)$ were always drunk and 10/49 $(20.4 \%)$ sometimes drunk when having casual sex. In this group $9 / 58(15 \cdot 5 \%)$ always used a condom with a casual sex partner abroad, while $21 / 62(33.9 \%)$ used it regularly when having sex with a prostitute.

Among the male IVDUs, 4/7 (57.1\%) were always drunk (female: $4 / 10 ; 40 \%$ ) and $2 / 7$ $(28.6 \%)$ sometimes when having casual sex (female: $3 / 10 ; 30 \%$ ). Furthermore, 3/14 $(21 \cdot 4 \%)$ always used a condom with a casual sex partner abroad.

Corresponding figures among homosexuals/bisexuals were, men always drunk 6/14 $(42.9 \%)$, women always drunk (0), men drunk sometimes $5 / 14(35 \cdot 7 \%)$ and women drunk sometimes $3 / 5$ (60\%). Among male homosexuals/bisexuals, $4 / 10 \quad(40 \%)$ had always used barrier protection abroad.

\section{Discussion}

Most of the casual sexual practice took place within Europe. Men having sex with men were more inclined to report casual sexual activity in north Europe where the majority of those already infected with HIV were homosexual/bisexual men. The IVDUs reported a casual sex partner more frequently in south Europe than any of the other groups. In Spain and Italy the majority infected with HIV were just IVDUs. ${ }^{7}$ Men reporting sex with prostitutes stated that such activities occurred frequently in Germany and Denmark. In addition, casual sexual activity outside the western world was mainly with prostitutes.

Table 2 Continental geography and number of persons with casual sex

\begin{tabular}{|c|c|c|c|c|c|}
\hline & \multicolumn{2}{|c|}{ Sex with prostitutes } & \multirow{2}{*}{$\begin{array}{l}\text { Homosexuals/ } \\
\text { bisexuals }\end{array}$} & \multirow{2}{*}{$\begin{array}{l}\text { Prostitutes/ } \\
\text { IVDUs }\end{array}$} & \multirow{2}{*}{$\begin{array}{l}\text { "other hetero- } \\
\text { sexuals" }\end{array}$} \\
\hline & paid/unpaid sex & paid sex & & & \\
\hline $\begin{array}{l}\text { Europe } \\
\text { North Europe } \\
\text { South Europe } \\
\text { USA (A) } \\
\text { C/S-America (B) } \\
\text { America }(A+\text { B) } \\
\text { Asia } \\
\text { Africa } \\
\text { Develop.Count } \\
\text { Total Persons }\end{array}$ & $\begin{array}{r}47(75 \cdot 8 \%) \\
41(66 \cdot 1 \%) \\
24(38 \cdot 7 \%) \\
7(11 \cdot 3 \%) \\
17(27 \cdot 4 \%) . \\
19(30 \cdot 6 \%) \\
18(29 \cdot 0 \%) \\
7(11 \cdot 3 \%) \\
30(48 \cdot 4 \%) \\
62\end{array}$ & $\begin{array}{r}41(66 \cdot 1 \%) \\
38(61 \cdot 3 \%) \\
7(11 \cdot 3 \%) \\
4(6 \cdot 5 \%) \\
16(25 \cdot 8 \%) \\
16(25 \cdot 8 \%) \\
18(29 \cdot 0 \%) \\
7(11 \cdot 3 \%) \\
29(46 \cdot 8 \%) \\
62\end{array}$ & $\begin{array}{c}14(63.6 \%) \\
11(50.0 \%) \\
7(31.8 \%) \\
2(9 \cdot 1 \%) \\
0(0.0 \%) \\
2(9.1 \%) \\
0(0.0 \%) \\
0(0.0 \%) \\
0(0.0 \%) \\
22\end{array}$ & $\begin{array}{c}13(61 \cdot 9 \%) \\
11(52 \cdot 4 \%) \\
11(52 \cdot 4 \%) \\
2(9 \cdot 5 \%) \\
0(0 \cdot 0 \%) \\
2(9 \cdot 5 \%) \\
0(0 \cdot 0 \%) \\
0(0.0 \%) \\
0(0.0 \%) \\
21\end{array}$ & $\begin{array}{c}138(27 \cdot 8 \%) \\
68(13 \cdot 7 \%) \\
92(18 \cdot 5 \%) \\
22(4 \cdot 4 \%) \\
3(0 \cdot 6 \%) \\
25(5 \cdot 0 \%) \\
5(1 \cdot 0 \%) \\
4(0 \cdot 8 \%) \\
11(2 \cdot 2 \%) \\
497\end{array}$ \\
\hline
\end{tabular}

$\mathrm{C} / \mathrm{S}$-America $=$ Central And South America 
Homosexual men have been found to travel more abroad than other high risk groups in the population. ${ }^{6}$ Many studies discussing this issue have concluded that unprotected casual homosexual experience with a man in USA was the primary way that HIV was carried to many west European countries. ${ }^{10}$ Studies report low travelling activity abroad among IVDUs compared with other groups. ${ }^{6}$

In this study the homosexuals/bisexuals and IVDUs/prostitutes reported the same number of casual sexual activity abroad from 1985-1989. The first HIV infected people in Norway were homosexuals, ${ }^{11}$ and they were also the first to change their behaviour. ${ }^{12}$

On 31 December 1990, a total of $12 \%$ (115) of HIV positive subjects in Norway had a history of sexual contact with prostitutes, of which $58 \%$ had taken place abroad. ${ }^{13}$

An obvious difference in casual sex between northern and southern Europe was that casual sex was more often, (5-6 times) unpaid in southern Europe. We do not have adequate figures from developing countries to be able to compare with the data from Europe. We did not ask the respondents about their purpose for travelling nor under what circumstances their sexual encounter took place.

In the future we should give the following advice: Do not get drunk, be very careful with your selection of partner, and do always practice safe sex. This advice should be given over and over again in Norway-not only at the vaccination offices as now.

Acknowledgement: This study had financial support from the University of Bergen, Norway.

1 Sato PA, Chin J, Mann JM. Review of AIDS and HIV infection: global epidemiology and statistics. AIDS 1989;3(Suppl. 1):S301-S7

2 Anderson RM, May RM, Boily MC, et al. The spread of HIV-1 in Africa: sexual contact patterns and the predicted demographic impact of AIDS. Nature 1991;352. 581-9.

3 Gerstoft J, Malchow-Møller A, Bygbjerg I, et al. Severe acquired immunodeficiency in European homosexual men. $B M \Im$ 1982;285:17-19.

4 Ryan MP. Aids in Thailand. Med f Aust 1991;154:282-4. Carswell JW, Lloyd G, Howells J. Prevalence of HIV-1 in east African lorry drivers. AIDS 1989;3:759-61.

6 Rezza G, Greco D. AIDS: drug addicts, homosexual Rezza G, Greco D. AIDS: drug addicts, homose
males and international travel. $A I D S$ 1987;1:191.

7 Global Programme on AIDS. Current and future dimensions of the HIVIAIDS pandemic. A capsule summary. Genève: WHO, 1991:1-15.

8 Siegel S. Nonparametric Statistics for the Behavioral Sciences. Tokyo: McGraw-Hill, 1959.

9 StatView. The Graphic Statistics Utility for the Macintosh. Calabas, Ca. Brainpower, 1985.

10 Fouchard JR, Schmidt KW, Krasnik A. HIV-infektion blandt bøsser og biseksuelle mænd i Danmark. Ugesk Lager 1989;151:613-6.

11 Lystad A. AIDS-tilfeller i Norge. MSIS-rapport. Meldesystem for Infeksjonssykdommer. Statens Institutt for Folkehelse, Norge 1986;15.

12 Nilsen $\emptyset$, Hasseltvedt V, Lystad A. AIDS-situasjonen Norge pr. 31. desember 1992. MSIS-rapport. Norge pr. 31. desember 1992. MSIS-rapport. Meldesystem for Infeksjonssykdom

13 Hasseltvedt V, Lystad A, Nilsen $\emptyset$. HIV positive personscontact with prostitutes-as monitored by the National HIV notification system. 11th British-Scandinavian Conference on Infectious Diseases. Gothenburg 1991. 